\title{
Integrating Technologies Into Teaching and Learning Mathematics at the Beginning of Secondary Education in Austria
}

\author{
Robert Weinhandl ${ }^{1 *}$, Tony Houghton ${ }^{1}$, Edith Lindenbauer ${ }^{2}$, Martin Mayerhofer $^{3}$, Zsolt Lavicza ${ }^{1}$, \\ Markus Hohenwarter ${ }^{1}$ \\ ${ }^{1}$ Linz School of Education, STEM Education, Johannes Kepler Universität Linz, Austria, Altenberger Straße 69, A-4040 Linz, \\ AUSTRIA \\ 2 University College of Education Upper Austria, Department of Mathematics Education, Kaplanhofstraße 40, A-4020 Linz, \\ AUSTRIA \\ ${ }^{3}$ Universität Wien, Fakultät für Mathematik, Austria, Oskar-Morgenstern-Platz 1, 1090 Wien, AUSTRIA
}

Received 6 October 2021 - Accepted 19 November 2021

\begin{abstract}
Modern technologies have become an integral part in our society and are increasingly shaping the teaching of mathematics at every level of education. In Austria, the academic school year 2021/22 will undergo an extensive digitalisation; all students who start secondary school will be equipped with a digital device. Our paper reports on anticipated concerns and benefits of mathematics teachers who are required to integrate technologies into teaching mathematics at the first year of secondary education. We conducted an exploratory interview study with secondary mathematics teachers before schools received their digital devices. The data was analysed with techniques based on grounded theory approaches. We discovered that for teachers the anticipated concerns and benefits were: (A) discrimination of students by technologies, (B) by using technologies, students may lose basic mathematical knowledge and skills, (C) individual and playful acquisition of new technological competencies by teachers, and (D) using technologies to enhance differentiation and individualisation in mathematics teaching. One of the key findings of our study is that mathematics teachers in Austria feel capable enough to integrate technologies into the teaching and learning of mathematics at the beginning of secondary education and do not express the need for further technical training. This finding contradicts previous studies and provides a starting point for future investigations.
\end{abstract}

Keywords: technology-enhanced mathematics teaching, teacher beliefs, integrating technologies

\section{INTRODUCTION}

In the academic year 2021/2022 in Austria, 10-yearold students in first year secondary school will be equipped with either laptops or tablets with a digital pen and keyboard. These digital devices will be owned by students for a contribution of $20-25 \%$ of the purchase price. In this way, approximately 150,000 digital devices will be purchased and distributed to students during the winter semester in upcoming year as substantial government contribution of 250 million euros. Through this process, schools still trail society because young people cannot picture a life without technologies
(Ferchhoff, 2007) and this initiative aims, among many other things, for schools to catch up with everyday uses of technologies. Here, mathematics education has a unique role because using technologies such as calculators, spreadsheets or apps has a long tradition (Larkin \& Calder, 2016). In addition to the long tradition of using technologies in teaching and learning mathematics, there is also a long list of barriers that can be encountered when integrating technologies into teaching and learning. According to Bingimlas (2009), widespread barriers include lack of teacher confidence, lack of teacher competencies and lack of access to resources. To some extent, these results were confirmed

(c) 2021 by the authors; licensee Modestum. This article is an open access article distributed under the terms and conditions of the Creative Commons Attribution License (http://creativecommons.org/licenses/by/4.0/). 


\section{Contribution to the literature}

- Mathematics teachers in Austria mainly use informal approaches to professional development for using technologies in teaching mathematics.

- Mathematics teachers still associate technologies for teaching and learning mathematics almost exclusively with calculators, spreadsheets or drill and practice programs.

- Mathematics teachers fear that using technologies in teaching and learning mathematics will prevent students from learning basic mathematical skills.

- Current technology developments such as augmented reality or 3D printing are not associated by Austrian mathematics teachers with using technologies in teaching and learning mathematics.

- Mathematics teachers in Austria feel capable enough to integrate technologies into teaching and learning; if there is a need for further training, mathematics teachers organise this further training themselves or use informal networks.

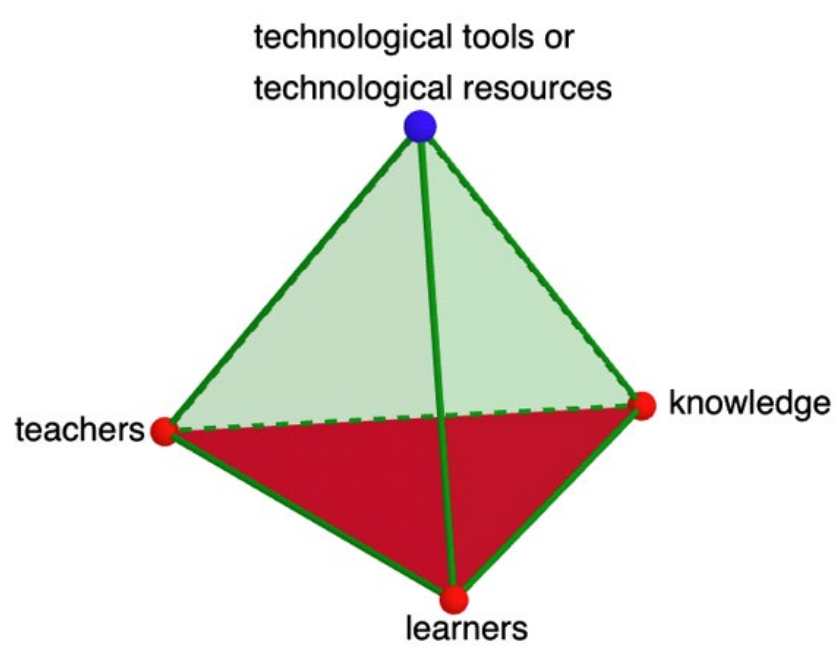

Figure 1. The didactic tetrahedron modified after Trgalová et al. (2018)

by the study on barriers regarding using e-learning by mathematics teachers during the first Corona wave by Mailizar et al. (2020). This study indicates that lack of teacher confidence and lack of teacher competencies were the teachers' main obstacles concerning using technologies while the first Corona wave. Teachers' lack of confidence and competencies are closely related to teachers' anticipated concerns and benefits of integrating technologies into teaching and learning mathematics, as well as to teachers' beliefs about using technologies for teaching and learning mathematics, which are the focus of our study.

Already, in the late 1990's, a research group at the conference of the European Society for Research in Mathematics Education (CERME) focused on using technologies showing also that there is a long tradition of scientific interest in this. According to Trgalová et al. (2018), integrating technologies adds a component to the didactic triangle of teachers, learners and knowledge. Through this extension, the didactic triangle (see Figure 1 , red base area) becomes a didactic tetrahedron (see Figure 1) in which teaching and learning mathematics also become more extensive and multi-layered. This more extensive and multi-layered setting of teaching and learning mathematics can be understood as a techno-mathematical learning environment. The term techno-mathematical learning environment, adapted from Hoyles et al. (2010), and Kent et al. (2005), describes a learning environment that can be characterised as modern and IT-based in which teachers and students are fluent in the language of mathematical inputs and outputs to technologies, and can interpret and communicate with them. According to Jacinto and Carreira (2017), for students to solve mathematical problems in such a learning environment, students need the skills of problem solving with mathematics and technologies, in this specific case GeoGebra. The focus on GeoGebra is of particular importance for our case, as the GeoGebra software package was invented in Austria and is a very widely used tool in Austrian schools. Further layers of a techno-mathematical learning environment and technology-enhanced teaching and learning mathematics are addressed in Section Integrating Technologies into Teaching and Learning Mathematics.

According to Lemmer (2013), concerning technologyenhanced learning environments, the focus should not only be on technologies but on learning processes of which the central component of any school learning process is the teacher. Following Selter et al. (2015), teachers' beliefs are a key element in this process and form the centre of our qualitative study which started before integrating technologies at the beginning of secondary education and pursues the following research question:

What are the anticipated concerns and benefits of mathematics teachers before integrating modern technologies into their teaching and learning of mathematics at the first grade of secondary school?

By modern technologies for teaching and learning mathematics we consider contemporary hardware products such as pads with keyboard, digital pen and internet access as well as mathematical (e.g., computer algebra systems or 3D geometry software packages) and 
general (e.g., learning or content management systems) software packages. Understanding mathematics teachers' anticipated concerns and benefits could have both practical as well as scientific importance and be used by software and content developers to design and improve their teaching and learning environments for lower secondary mathematics. Furthermore, a comprehensive knowledge of teachers' anticipated concerns and benefits regarding integrating modern technologies into teaching and learning mathematics at the beginning of secondary education should contribute to a better understanding of mathematics teachers' beliefs. According to A. G. Thompson (in Philipp, 2007), it is important to investigate mathematics teachers' beliefs in order to make explicit teachers' implicit conceptions about teaching, learning and the nature of mathematics, because these implicit perspectives influence approaches to and interpretations of the work of mathematics education researchers. Mathematics teachers' beliefs may be subject to significant change since both national education documents (Breit et al., 2019; Bruneforth et al., 2016) as well as documents from the EU and OECD (Barana et al., 2017) call for using modern technologies and these technologies are made extensively available on a large scale at the beginning of secondary education. Our study, focusing on examining anticipated concerns and benefits of mathematics teachers concerning integrating technologies into teaching and learning, places such potential changes of mathematics teachers' beliefs at the centre of our investigation. We analysed the collected data using a grounded theory approach to identify mathematics teachers' anticipated concerns and benefits before implementing technologies.

\section{THEORETICAL BACKGROUND}

\section{Using Technologies in the Teaching and Learning of Mathematics}

There is an extensive literature on the use and misuse of technologies in mathematics education (Larkin \& Calder, 2016). Using technologies is becoming highly important for mathematics and also science education in the 21st century including calculators, computers or virtual apps (Larkin \& Milford, 2018). According to Flood et al. (2020), technologies designed to support human-computer interactions will be key to acceptance. Such interactions could include, for example, using augmented reality. Attard et al. (2020) highlight a continuously increasing range of technologies used in teaching and learning mathematics. The rapid development of technologies has resulted in a drastic change in mathematics teaching and learning (Inayat \& Hamid, 2016). According to Donevska-Todorova \& Trgalova (2017), using technologies in mathematics education is a complex phenomenon characterised by vivid dynamics. In this context, Sinclair (2020) summarises that using modern technologies leads to a change in the way mathematics is learned and the content that is learned.

Such drastic change in mathematics education means that teachers have to adapt their methods and approaches to teaching. Especially when a top-down approach imposes such an adaptation of teaching and learning (in our case, through the widespread provision of digital devices), it could be accompanied by great anticipated concerns and benefits on the part of teachers. These could be key to their successful implementation.

\section{Integrating Technologies into Teaching and Learning Mathematics}

Borba et al. (2016) identified four phases of using technologies in mathematics. The third and fourth phases are likely to be of particular interest for our study. These phases are characterised by changes in communication and the way we connect with each other (third phase), as well as quantitative (e.g., broadband) and qualitative (e.g., Web 2.0 or MOOCs) changes in the internet, better opportunities for collaborative learning, personalisation of the internet through personal devices and cloud storage and computing (fourth phase). Thus, the third and fourth phases represent visions of what mathematics classrooms could look like when technologies have been integrated into the teaching and learning mathematics.

Almanthari et al. (2020), and Weinhandl et al. (2021) summarised in their studies of mathematics education in the homeschooling-driven Covid era that integrating new technologies is not always successful or effective. Especially when schools, teachers and students have little experience using technologies in formal learning settings, this causes significant challenges for schools, teachers and students which can be characterised as hard or soft factors.

In our study, hard factors are determined by the digitalisation initiative of the Ministry of Education in Austria. At the beginning of secondary school, every student receives his or her digital device, which should be used for teaching and learning. This specification of the hard factors means that the soft factors, the beliefs or personal preferences, and the teachers' competencies are critical when integrating technologies into teaching and learning. Accordingly, we focus our study on the soft factors, in particular the anticipated concerns and benefits of mathematics teachers in integrating technologies into teaching and learning.

\section{Teachers' Knowledge and Beliefs}

Following the TPACK model of Mishra \& Koehler (2006, see Figure 2), teachers in a technology-enhanced learning environment need knowledge in the respective areas of the model (pedagogical, technological and content knowledge). Content knowledge is knowledge 
about the actual subject matter to be taught or learned, in our case that is knowledge about topics in the secondary school mathematics curriculum; pedagogical knowledge is in-depth knowledge about the processes and practices or methods of teaching and learning; and technological knowledge is knowledge about standard technologies, such as books, chalk and blackboard, and more advanced technologies, such as the Internet and digital video, with our study focusing on the latter. Most importantly, teachers need knowledge when two (PCK, TCK and TPK) or all three bodies of knowledge (TPACK) are combined. Technological content knowledge (TCK) is knowledge about the ways in which technologies and content are interrelated. This knowledge is closely related to Sinclair's (2020) summary that using technologies also changes the mathematical content that is learned. Technological pedagogical knowledge (TPK) is knowledge about the existence, components and capabilities of different technologies as they are used in teaching and learning situations and, conversely, knowledge about how teaching might be changed by the use of certain technologies. This knowledge is also of specific relevance to the teaching and learning mathematics, as according to Attard et al. (2020), more and more technologies are being integrated into the learning of mathematics and, among other things, this is changing the teaching and complexity of mathematics (DonevskaTodorova \& Trgalova, 2017; Sinclair, 2020). Pedagogical content knowledge (PCK) is the merging of content and pedagogy into an understanding of how certain aspects of subject matter are organised, adapted and presented for instruction and goes back to Shulman (1986). Technological pedagogical knowledge (TPCK) is an emergent form of knowledge that transcends all three components of knowledge and following Mishra and Koehler (2006) 'TPCK is the basis of good teaching with technology'. In an updated version of the TPACK model (Mishra, 2019), teachers' conteXtual knowledge (see Figure 2, outer circle) is also included. Mishra (2019) interprets conteXtual knowledge as another knowledge domain and describes this as 'everything from a teacher's awareness of available technologies, to the teacher's knowledge of the school, district, state, or national policies they operate within'.

According to this updated version of the TPACK model, teachers' TPACK knowledge is embedded in teachers' conteXtual knowledge. The individual parts of the TPACK model constantly interact behind the background of a teacher's conteXtual knowledge.

According to Thurm and Barzel (2020), mathematics teachers' beliefs are a key component of this. Their study indicates that teachers' use of technologies increases in a supportive environment, thereby impacting teachers' technology-related beliefs. Ottenbreit-Leftwich et al. (2010), and Smith et al. (2016) argue similarly. According to their studies, teachers' beliefs influence, among other

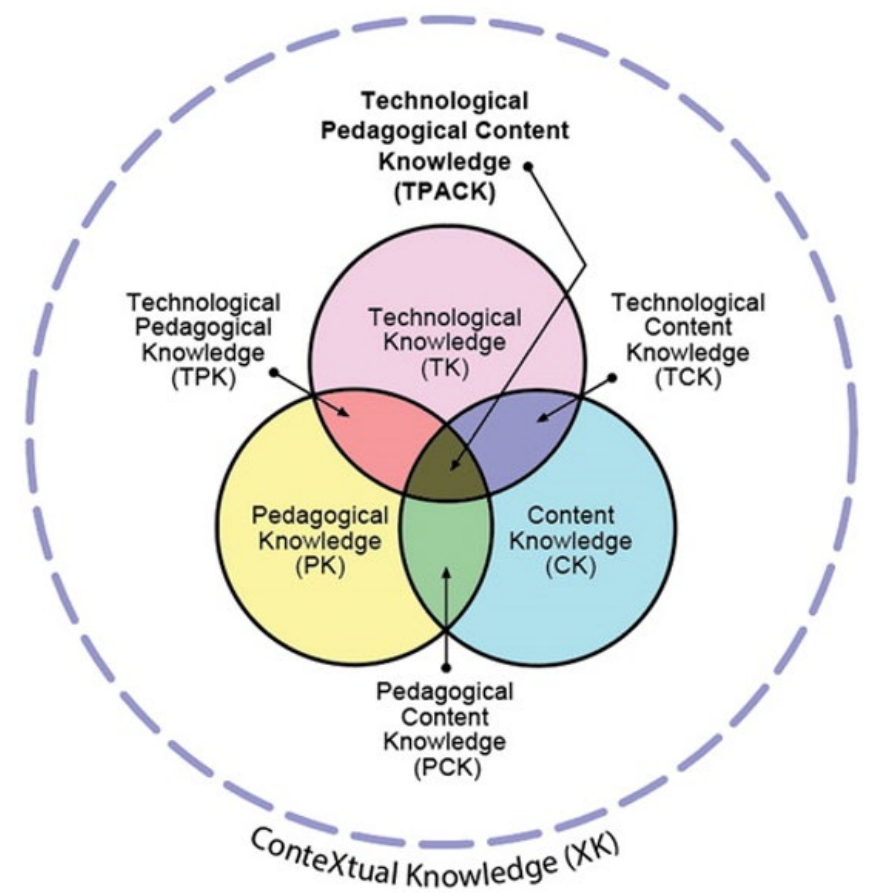

Figure 2. Updated version of the TPACK model according to Mishra (2019)

things, the behaviour and thinking of mathematics teachers, whether technologies are used in the classroom, and the choice of and how technologies are used in teaching and learning. Smith et al. (2016) also indicate that teachers' beliefs about using technologies may also depend on teachers' TPACK level.

In their study on teacher beliefs about technology use, $\mathrm{O}^{\prime} \mathrm{Neal}$ et al. (2017) indicate that teachers need more support in integrating technologies. This need for support could be of high importance, as according to Sipilä (2014), it is the teachers who decide whether and in which form technologies are integrated into teaching and learning. The purposes of using technologies in teaching and learning mathematics include: resources distribution, organising and structuring materials, demonstrations, testing or assessing student knowledge and competencies, discovery and learning, communication between teacher and students or between students themselves, working cooperatively or collaboratively, monitoring student activities and providing feedback and guidance (Borba et al., 2016; Drijvers et al., 2010; Lavicza et al., 2015; Trgalová et al., 2018; Yeo, 2020). According to Goos et al. (2003), the roles that technologies can take on in this process in line with teachers' beliefs are those of master, servant, partner, or extension of self.

The importance of TPK and TPACK in our study stems from the fact that teaching and learning mathematics requires different and, at times, additional competencies from teachers than would be the case with using a paper and pencil approach. Since integrating laptops or tablets with a digital pen and keyboard into teaching and learning also changes the environment of 
teaching and learning processes, teachers' conteXtual knowledge is vital for teaching and learning in schools. Teachers' beliefs together with technological pedagogical knowledge and competencies will determine if technologies are integrated into teaching and learning, the purposes for which teachers use technologies in teaching and learning mathematics and the anticipated concerns and benefits that mathematics teachers have in this regard. The novelty and significance of our study stems, among other things, from the circumstance that in only very rare cases (e.g., Uruguay; Vitabar et al., 2019) technologies are made available to students and teachers nationwide. Thus, the framework of our study offers the opportunity to investigate mathematics teachers' beliefs about using technologies, in our specific case the anticipated concerns and benefits that mathematics teachers have concerning integrating technologies, on a national scale.

\section{CONTEXT AND METHODOLOGICAL BACKGROUND OF OUR STUDY}

\section{Trigger of Our Study and Situation at the Beginning of Secondary Education in Austria}

The context of our study is fundamentally new compared to previous years of teaching and learning mathematics at the beginning of secondary education. This novelty can potentially change both the way of learning and the content to be learned. With the academic year 2021/2022, at the beginning of secondary school, the Ministry will provide students with modern technologies such as laptops or pads with a digital pen and keyboard. Students' parents will be asked to contribute $20 \%$ to $25 \%$ of the purchase price. Also, since the outbreak of the Covid pandemic, the Ministry has provided access to learning/content management systems such as MS Teams or Moodle. In addition to paper students' books, teachers can use eBooks or eBooks Plus for their teaching, and the Ministry provides a resource database of teaching, learning and exercise resources. Since using high-quality technologies in the compulsory standardised school-leaving mathematics examination at the end of secondary school has been mandatory for several years, using mathematical software packages such as GeoGebra or scientific calculators like TI-Nspire is an integral part of teaching and learning mathematics in upper secondary school.

In conjunction with our study, Johannes Kepler University and the GeoGebra group develop interactive learning resources for teaching mathematics at the beginning of secondary school (approximately 10-yearold students). These interactive learning resources provide students with just-in-time feedback on whether tasks have been solved correctly or incorrectly, offer help to students if tasks have been solved incorrectly, aim at supporting students in developing mathematical concepts, document students' learning progress and offer teachers the opportunity to monitor students' activities in real-time on their computers to provide individualised support to students if necessary. Our research aims to find out how modern technologies in general, and learning resources for teaching mathematics in our study in particular, could be integrated at the beginning of the secondary level. To do this, we focus our study on the mathematics teachers who have modern technologies omnipresent at their disposal at the beginning of secondary education in the academic year 2021/2022.

\section{Participants in Our Study}

A total of 14 teachers from six schools participated in our study. The schools are located in both urban and rural areas. In selecting the schools, care was taken to choose schools with students from both potentially higher and lower socio-economic backgrounds. Schools where we assume potentially higher socio-economic backgrounds are private schools and schools in urban city centres. Schools that we assume to have a potentially lower socio-economic background are those located in regions affected by high out-migration. We chose a private school and a school in the city centre of a large city as representatives of schools with a higher socioeconomic background. As representatives of schools with a potentially lower socio-economic background, we chose two schools from out-migration regions close to the former Iron Curtain. The other two schools cannot be assigned to these two poles and thus correspond to the broad average of secondary schools.

As teachers for our study, we selected those from the schools concerned who are teaching a first-grade secondary mathematics class in the current academic year. Of the 14 teachers in our study, eleven are women, and three are men. This gender distribution favours women over men more than is usual for secondary school teaching staff. In terms of professional experience, we chose teachers at the beginning and in the middle of their careers for our study. The teachers in our study are thus from 28 to 49 years old.

\section{Focus and Guideline of Our Qualitative Interview Study}

Our study aimed to identify anticipated concerns and benefits that mathematics teachers have concerning integrating technologies at the beginning of secondary education. A qualitative interview study was conducted to identify teachers' anticipated concerns and benefits. Teachers' feedback is analysed using grounded theory approaches. To collect the teachers' feedback, we used a semi-structured guideline. Questions we asked the teachers in our study were on the following three thematic complexes:

- What are anticipated concerns and benefits regarding teaching and learning mathematics 
with modern technologies at the beginning of secondary school?

- What support is required for preparing to teach mathematics with modern technologies at the beginning of secondary education?

- How does one prepare for teaching mathematics in the coming school year, and what changes are made to one's teaching as mathematics will be taught and learned in an environment with modern technologies in the coming year?

In the course of conducting the interviews, these thematic complexes were deepened, and individual focus areas were set following the teachers' answers, interests, or concerns. The three thematic complexes correspond to the everyday professional lives of teachers. To scientifically investigate phenomena of everyday professional life, it is typical to use the principles of grounded theory and interview study approaches (Charmaz, 2006; Glaser \& Strauss, 1999; Ridder, 2016). According to Charmaz (2006), our study can be attributed to a constructivist interpretation of grounded theory research. Constructivist grounded theory means that the research results depend on the researchers' perspectives and that knowledge of the current body of scientific knowledge is included in developing findings.

Interviews were conducted verbally and in writing. When the interviews were conducted purely verbally, the interview thread was given by us, the study's authors. The deepening within the individual thematic complexes was left up to the interviewed teachers. In the written and verbal interviews, the interviewed teachers were first sent the guiding questions, which the interviewed teachers answered in writing. Afterwards, we contacted the interviewees and verbally elaborated on the written answers with the interviewees. After conducting the interviews, all information was transcribed by us, the authors. It is characteristic of interview studies and research using grounded theory approaches that different data collection methods and different data are used (Charmaz, 2006; Glaser \& Strauss, 1999; Ridder, 2016). Different data collection methods and different data were used in our case study following theoretical sampling. Theoretical sampling, which is one of the centrepieces of grounded theory research, states that new data are collected in line with the current state of knowledge of a study and the data, data collection tools and methods are adapted following the aim of the research and the state of the study (Charmaz, 2006; Glaser \& Strauss, 1999; Strauss \& Corbin, 1990).

\section{Using a Case Study Approach to Investigate the Integration of Technologies}

As our study focuses on the anticipated concerns and benefits of certain selected teachers, i.e., on understanding individual situations, our research can be characterised as a case study (Cohen et al., 2007; Eisenhardt, 1989). According to Cohen et al. (2007), it is typical for a case study that real people in real settings experience targeted interventions. These real people in real settings then form a limited system. In our study, the mathematics teachers and the mathematics classes at the beginning of secondary school form the real people in real settings. Our study's intervention is the implementation of modern technologies at the beginning of secondary education. In this intervention, we examine teachers' anticipated concerns and benefits about the intervention.

According to Eisenhardt (1989), extreme cases may contain important information regarding extending the body of knowledge and theory building. For this reason, we overemphasised the two ends of the socio-economic continuum of schools, i.e., schools with a potentially very high and a very low socio-economic background. This overemphasis corresponds to purposive sampling, which is typical for case studies (Ridder, 2016) and grounded theory approaches (Charmaz, 2006; Glaser \& Strauss, 1999; Strauss \& Corbin, 1990).

In terms of methodological background, our study used approaches from a qualitative interview study (Braun \& Clarke, 2006; Ezzy, 2002) and grounded theory (Charmaz, 2006; Strauss \& Corbin, 1997). Since the questions in our study were asked in a very open manner and the teachers in our study were able to answer in their own words as well as to set their priorities within the given topics, our data collection can be classified as a non-standardised interview technique (Gläser \& Laudel, 2010). This non-standardised approach to interviewing resulted in complex texts based on the verbal and written feedback of the teachers in our study (Wrona, 2005). According to Charmaz (2002), there is a close connection between grounded theory research and qualitative interview studies. In line with this close connection between the two approaches, principles of grounded theory and qualitative interview studies were used in our data analysis. In particular, the techniques of grounded theory approaches were used in the analysis of the data and the formation of results.

\section{Data Analysis and Formation of Results}

We used a three-step process typical of grounded theory approaches (Charmaz, 2006; Glaser \& Strauss, 1999; Strauss \& Corbin, 1997): 1) open coding, 2) axial coding, 3) selective coding.

In a first step, we examined the new data in line with the inductive thematic principles (Braun \& Clarke, 2006; Ezzy, 2002) and the open coding approaches (Charmaz, 2006; Strauss \& Corbin, 1997). This approach aimed to break up the new data and develop initial units of meaning. Using the inductive thematic principles and open coding approaches resulted in 76 first sense units. An extract of the first sense units is given in Table 1 in 
Table 1. Prototypical excerpts from the coding book

\begin{tabular}{|c|c|c|c|}
\hline $\begin{array}{l}\text { open codes or first sense } \\
\text { units }\end{array}$ & $\begin{array}{l}\text { open codes of a higher level } \\
\text { of abstraction }\end{array}$ & categories of axial coding & core categories \\
\hline $\begin{array}{l}\text { Private technologies of the } \\
\text { students }\end{array}$ & $\begin{array}{l}\text { Better structuring through } \\
\text { technologies }\end{array}$ & \multirow{2}{*}{$\begin{array}{l}\text { independence of teaching } \\
\text { and learning processes in } \\
\text { terms of time and space }\end{array}$} & $\begin{array}{l}\text { discrimination of students by } \\
\text { technologies }\end{array}$ \\
\hline Basic digital skills of the & Higher quality of tasks & & by using technologies, \\
\hline students & Data protection / legal & \multirow{3}{*}{$\begin{array}{l}\text { Technological background of } \\
\text { mathematics teachers as an } \\
\text { advantage }\end{array}$} & students may lose basic \\
\hline Distraction through & concerns & & mathematical knowledge and \\
\hline technologies & Lack of technology & & \\
\hline Videos as learning materials & competencies among & Technologies as an & individual and playful \\
\hline Self-selecting tasks & students as a problem & additional physical and & acquisition of new \\
\hline Bugs in digital resources & School equipment as & $\begin{array}{l}\text { cognitive burden } \\
\text { Slow and planned }\end{array}$ & $\begin{array}{l}\text { technological competencies } \\
\text { by teachers }\end{array}$ \\
\hline$\cdots \cdots$ & Dotuenteck & $\begin{array}{l}\text { introduction of technologies } \\
\text { to students } \\
\ldots . .\end{array}$ & $\begin{array}{l}\text { using technologies to } \\
\text { enhance differentiation and } \\
\text { individualisation in } \\
\text { mathematics teaching }\end{array}$ \\
\hline
\end{tabular}
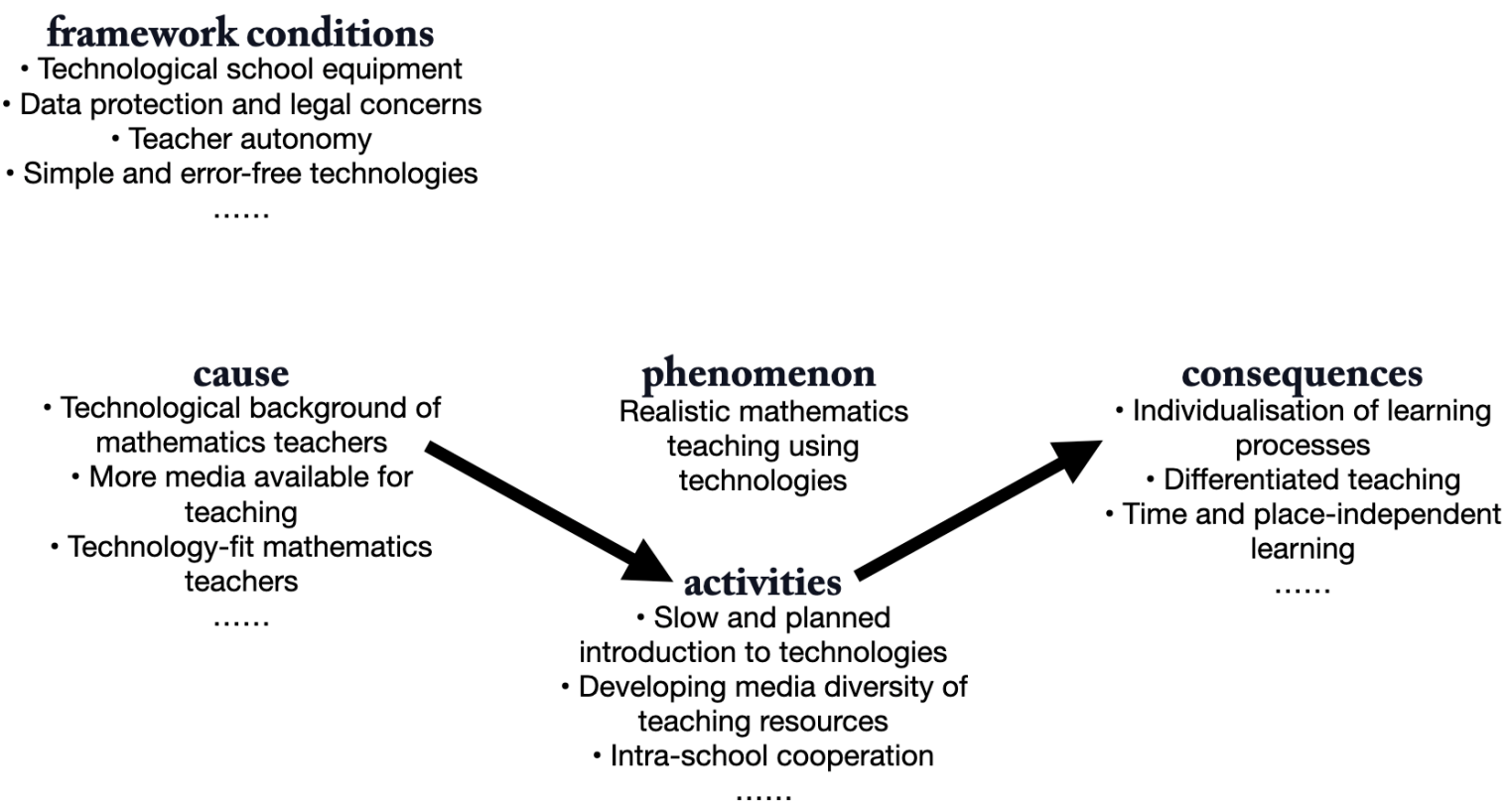

Figure 3. Prototypical procedure for axial coding

the first column. These 76 first sense units were clustered based on similar descriptions and definitions and given a new keyword. This bundling of first sense units was intended to increase generalisability and abstraction and resulted in 26 open codes of a higher level of abstraction (Table 1, second column).

In the second step, we used axial coding techniques to analyse the open codes of a higher level of abstraction. Axial coding represents a core part of grounded theory research (Charmaz, 2006; Mey \& Mruck, 2011). In axial coding, around a central phenomenon (a central open code of a higher level of abstraction), the other open codes of a higher level of abstraction are arranged by cause, activities, consequences and framework conditions. Axial coding aims to synthesise the open codes again and thus achieve a higher level of generalisability and abstraction (Breuer et al., 2009; Charmaz, 2006; Mey \& Mruck, 2011). A prototypical example of axial coding is shown in Figure 3.

Selective coding is used to test initial assumptions about the research question and discover and close any research gaps. In selective coding, the categories obtained from axial coding are placed in connection or dependence. Through the interrelation and interdependence of categories, core categories of the study are to be developed (Breuer et al., 2009; Charmaz, 2006; Rosenkranz, 2017). In the course of our study, using the techniques of selective coding, the core categories (A) discrimination of students by technologies, (B) by using technologies, students may lose basic mathematical knowledge and skills, (C) individual and playful acquisition of new technological 
competencies by teachers, and (D) using technologies to enhance differentiation and individualisation in mathematics teaching could be identified.

\section{RESULTS}

In the following section, the core categories of our study are outlined in more detail and backed up with original quotes from our interviews. We translated the original quotes from our study into English. In addition to the quotes, we provide information on whether the interviewed teacher is male $(\mathrm{m})$ or female $(\mathrm{f})$, whether the teacher is at the beginning (beg) or in the middle (med) of his or her professional career, and whether the teacher teaches in a school with a high (h), average (a) or low (l) socio-economic background.

\section{Discrimination of Students by Technologies}

For all teachers in our study, i.e., regardless of the school's socio-economic status, the potential discrimination of students through using technologies in teaching and learning mathematics was a central theme. It was assumed that students at the beginning of secondary school have very different skills in using technologies. These different expected skills in using technologies concerned using technologies in general and using technologies purposefully in teaching and learning environments in particular. Using technologies in general means that teachers in our study are concerned that while some students privately own and are proficient in using modern technologies, other students are potentially holding a technological device in hand for the first time in school.

[m-med-1] It can be assumed that some students will not be able to turn on the pad, and others (students) have one (device) at home themselves and are bored at the beginning.

In addition to the hardware component, teachers also have concerns about the different skills of using software and using the technologies for learning.

[f-med-a] Some (students) only play with them (technologies), the others (students) can do meaningful things with it (technologies).

Due to these different starting conditions, teachers fear that the gap between good and less good students could already widen in the first weeks of integrating technologies. Another potential discrimination that many teachers in our study fear is learning mathematics in a technology learning environment. In line with the feedback from teachers, both learning mathematics and learning to use technologies purposefully are described as cognitively demanding activities. Many teachers are concerned that good mathematics students are also good at using technologies and that poor mathematics students may also have problems using technologies purposefully.

[f-beg-h] Those students who are already good will also be good at using technologies, and the bad students have another hurdle (using technologies) to jump.

In addition to the cognitive burdens on students using technologies, the teachers also identified potential physical burdens on students. Teachers characterise the use of technologies in learning as potentially more tiring than technology-free learning. It is assumed that the fewer experiences students have with the purposeful use of technologies, the greater the risk of rapid fatigue in using them.

[f-med-a] Then, when students have their digital device for the first time in class, they become tired and less receptive just from working on the screen.

The teachers assume that less-skilled students also have less or no experience of using technologies purposefully. This potential disadvantage of less good students could, in turn, widen the gap between good and less good students.

[m-med-h] Good students often come from good backgrounds and already know about technologies; less good students often do not have this framework, so the already large gap widens even more.

Discrimination of students by technologies was a central theme of the teacher feedback. They assume that the previous experiences and private access to modern technologies are very different among the students. These differences in prior experience and access to technologies could cause large differences in students' technological skills and competencies at the beginning of secondary school in the purposeful use of technologies. This could widen the socio-economic gap between good and less good students using technologies.

\section{By Using Technologies, Students may Lose Basic Mathematical Knowledge and Skills}

A major concern of numerous teachers in our study was that by integrating modern technologies at the beginning of secondary school, students will not learn much basic mathematical knowledge and skills. The majority of teachers equate to using calculators, calculator functions, or computer algebra systems. By having a calculator tool at the students' disposal, in line with the teachers' opinions in our study, the students would not learn mental arithmetic or written arithmetic at all or not well.

[m-med-1] If students are now given tools to do arithmetic at the age of ten, simple arithmetic like 
the small one-by-one will probably never be learned; I don't know whether the policymakers want that.

By potentially not learning mental arithmetic or written arithmetic skills well or not at all, students would develop a mathematical gap at the beginning of secondary school, which would run through the entire school career of the students and will probably not be closed again.

[f-med-a] We already notice at the school-leaving examination that students can no longer solve simple arithmetic problems; if you give them (the students) digital devices at the beginning of secondary school, this will become even worse.

In the interviews of our study, we discovered that many teachers believe that using technologies is the cause of students' lack of numeracy skills or ability to estimate results in a task. Although all teachers in our study identified themselves as users and supporters of technologies in teaching and learning mathematics, this endorsement of using technologies was often accompanied by a but.

[f-beg-a] I like using technologies in teaching and learning mathematics, but...

[f-med-h] I often use technologies myself in my classes, but...

[f-med-a] Technologies are certainly an important part of our society and also mathematics education, but...

In addition to the reduced numeracy skills of students, many teachers in our study are concerned that by using technologies at the beginning of secondary school, students will not learn basic mathematical knowledge. The basic mathematical knowledge of students was divided into two parts by the teachers. First, basic mathematical knowledge is seen as learning mathematical formulas and properties of mathematical objects. Secondly, teachers describe a regular approach to solving problems and documenting the solution as basic mathematical knowledge or competency. Many teachers in our study equate having modern technologies at their disposal with being online. According to the teachers' opinions in our study, the omnipresence of the internet could lead to the situation that formulas or properties of mathematical objects are no longer learned or looked up in the student book, but that they are researched on the internet. Research on the internet is criticised by teachers in our study on the one hand because it means that students do not learn basic mathematical formulas by heart, and on the other hand, potential misinformation on the internet is a problem for teaching and learning mathematics. [f-med-a] If students can always look up everything [on the internet], then even the simplest things like [the formula for] calculating the volume of a cube will not be learnt.

[m-med-1] With the technologies, the students will do a lot of research on the internet, and on the internet, you can also find a lot of false information [...] and nonsense.

In addition to losing the ability to learn mathematical formulas and the properties of mathematical objects, teachers also fear that using technologies will fail to learn mathematical work early on, i.e., regular procedures for solving problems and documenting the solution path. Teachers explain this non-learning of mathematical work because technologies make it challenging to document the path to a solution. Along with not documenting the solution path, teachers in our study fear that students do not learn structured work at an early stage if at all. This lack of structure in mathematical work could lead to even more students having problems in mathematics lessons than is already the case.

[f-beg-a] At our school, the students will get laptops. A ten-year-old student cannot document his/her solution path with a laptop and will therefore never learn it.

A central concern is that students learn and deepen mathematical work and calculation skills at the beginning of secondary school, and that technologies in teaching and learning mathematics will decrease students' mathematical work and numeracy competencies.

\section{Individual and Playful Acquisition of New Technological Competencies by Teachers}

On the positive side, teachers in our study stated that implementing technologies at the beginning of secondary education will also lead to acquiring new knowledge and competencies. Here, many teachers emphasised the unique position of mathematics. Since 2015, using high-quality technologies (e.g., Computer algebra systems, dynamic geometry software or software for probability calculation) in the compulsory, standardised, nationwide written school-leaving examination in mathematics has been prescribed. As a result, mathematics teachers have extensive experience using technologies in upper secondary school. This knowledge should give mathematics teachers a starting advantage over other subjects. Despite this, the teachers indicate that using technologies at the beginning of secondary school (students are about ten years old) is different from using technologies when preparing for the final written mathematics examination (students are about 17 years old). 
[f-med-h] We (mathematics teachers) have been using technologies in the classroom for many years, especially in upper secondary school. So we certainly have a big starting advantage over, say history teachers. Still, it will be a little different whether I use technologies with Grade 5 students (14 years old) or Grade 1 students (10 years old).

If there is a need for further training in using technologies at the beginning of secondary school, the teachers in our study prefer individual learning following a trial-and-error approach or school-internal cooperation over institutionalised further training at institutes or universities. Individual learning using a trial-and-error approach means that they search for new technological tools or teaching approaches themselves, usually by conducting internet research. The tools or teaching approaches found in this way are then adapted to their lessons and integrated into mathematics teaching. If problems arise during the first use of the tools or teaching approaches, the tools or approaches are adapted accordingly if the problems are not too significant. In this context, many teachers in our study emphasised that any problems are anticipated when using new tools or approaches for the first time.

[f-beg-a] I look for new apps or great web pages for my lessons myself and then adapt them to my class. Of course, something can go wrong on the first try, but that can also happen when I teach using a chalk-and-talk approach.

In addition to individual learning, our teachers state that intra-school cooperation is also an essential part of professional development and has grown informally and independently over the years. This means that there is a mutual exchange and support for teaching aids, including exchanging information with colleagues on everything from newly found software to their lesson plans or schoolwork. This exchange usually takes place via email or at informal meetings.

[f-med-h] We have a great collaboration among the teachers in our school, especially the mathematics teachers. We exchange resources or even lesson plans in our own MS Teams group that we have set up, and you can always ask colleagues; this helps more than (formal) inservice training.

More technologies in teaching and learning mathematics mean that teachers are also required to have more knowledge and competencies. The teachers prefer individual and informal approaches to acquire technological-didactic knowledge and competencies over institutionalised offers from universities or institutes. On the one hand, the teachers of our study pursue the approach of independent search for new technological tools and then a trial-and-error approach when implementing these approaches in their teaching. On the other hand, teachers participate in informal school-internal cooperation in the course of which knowledge is passed on.

\section{Using Technologies to Enhance Differentiation and Individualisation in Mathematics Teaching}

The greatest hope of the teachers concerning integrating technologies at the beginning of secondary school is that this will make it easier to differentiate and individualise teaching. According to the feedback of the teachers, differentiation and individualisation of teaching should be realised through more autonomy of the teachers, media diversity, diversity of tasks, making mathematics closer to reality and more independent of time and place.

Teacher autonomy, in line with the feedback in our study, means that teachers no longer have to exclusively use explanations or tasks from the mathematics students' book.

[f-beg-a] I often used additional explanations and tasks now. Hopefully, through the students' technologies, this will also become easier in the classroom in the future.

In addition to more explanations and tasks, teachers hope that the constant presence of modern technologies will also allow more media to be integrated into teaching and learning mathematics. The more media mainly concerns instructional videos and interactive worksheets, which offer students feedback and tips in real-time.

[f-med-h] Through videos, the students can then also independently repeat the contents of the lessons, and I also want to try Flipped Classroom; I am already looking forward to that.

Prominent criticism teachers have of traditional teaching materials, such as the mathematics students' book, is that they are often full of pseudo-realistic tasks. Pseudo-realistic tasks are described by teachers as those tasks that want to establish a connection to reality but are far removed from the real everyday life of the students. By using technologies, teachers hope that they can choose from a larger pool of tasks and thus only integrate such tasks into their lessons that, in the opinion of the teacher, actually have a relation to reality for students. Also, teachers hope that actual artefacts or facts of the students' everyday life can be integrated into the lessons more easily by using modern technologies.

[m-med-h] With the new technologies, it is then easier for students to do a survey and collect data themselves. With paper and pencil, it has always been a hassle, but students like to be able to collect data themselves and do surveys at school. 
Another hope of the teachers is that mathematics lessons can be made more time and place independent, appropriate to students' age by using technologies. Modern technologies should primarily be used so that the acquisition of new mathematical content can also occur outside of the classroom or that newly learned content can be repeated or deepened outside of the classroom. Teachers in our study place great hope in the repetition and deepening of new content outside the classroom. For example, learning videos or tasks with automatic feedback should be used for this repetition or deepening of mathematical content.

[f-med-h] As I said earlier, I believe that the technologies make it easier to repeat and practise. With tablets, students can learn almost anywhere they want - in afternoon classes at school, at home or when they visit a schoolmate.

Differentiation and individualisation of mathematics teaching with the help of modern technologies should, in line with the feedback from the teachers in our study, be achieved by increasing the number of tasks. The increase concerns both the quantity and the quality of the tasks. A quantitative increase in the number of tasks should be achieved by no longer using only the students' books as a pool of tasks but by integrating tasks from different online and offline sources into the technological learning environment. A qualitative increase should be possible insofar as actual realistic tasks can be integrated into teaching and learning mathematics. No pseudorealistic tasks from the students' books have to be used any longer. Also, the teachers also hope that the learning process can be better adapted to students' needs by using technologies. This adaptation of the mathematics learning process to the needs of the students can happen through independent practice with digital tasks that give feedback in real-time or through more straightforward repetition of the lesson material.

\section{DISCUSSION AND CONCLUSIONS}

Analysing the data indicated that for teachers, before implementing technologies at the beginning of secondary school, the following themes were of interest: (A) discrimination of students by technologies, (B) by using technologies, students may lose basic mathematical knowledge and skills, (C) individual and playful acquisition of new technological competencies by teachers, and (D) using technologies to enhance differentiation and individualisation in mathematics teaching.

According to Attard et al. (2020), and Flood et al. (2020), the range of technologies used for teaching and learning is increasing. The same technologies are used by students for learning in school as well as outside the classroom, and new technologies can include augmented reality or technologies designed to support human-computer interactions. Despite a wide range of technologies, a blurring of the boundaries between technologies in schools and technologies for private use, and the knowledge that students will be equipped with modern technologies at the beginning of secondary education, teachers in our study still understand technologies to be traditional technologies such as calculators or spreadsheets. This traditional image meant that before integrating technologies into teaching and learning mathematics, we had to explain what we mean by the term technologies.

Multiple technologies such as virtual apps (Larkin \& Calder, 2016) or augmented reality (Flood et al., 2020) mean that content can be presented in multiple ways and then students have multiple opportunities for learning mathematics. According to Donevska-Todorova and Trgalova (2017), these various representations and learning possibilities of mathematical content mean that teaching and learning with technologies can be described as a complex phenomenon. For teachers in our study, these multiple possibilities of teaching and learning mathematics constitute both great opportunities and significant potential risks. The opportunity of the manifold possibilities is seen because teaching and learning mathematics with technologies could facilitate differentiation and individualisation of learning processes. Differentiation and individualisation of learning processes could happen through tasks of different difficulty, a different number of tasks or through temporal flexibility of learning processes. The risk of integrating technologies is seen as an additional burden for students. This additional burden can mean, for example, that students have to learn to use technologies in general and mathematics-specific apps in particular, in addition to mathematical content.

Using Web 2.0 functionalities, approaches of technology-supported collaborative learning or personalisation of the internet in teaching and learning mathematics (Borba et al., 2016) lead to teachers needing additional knowledge and competencies. This new knowledge and competencies are reflected and explained in the TPACK model (Mishra \& Koehler, 2006). Our study showed that teachers prefer individual and school-internal approaches to this knowledge and competency acquisition. For teachers in our study, individual and in-school approaches to knowledge and competency acquisition mean that informal in-school networks are used for knowledge sharing and thus professional development.

According to Almanthari et al. (2020), Thurm and Barzel (2020), and Weinhandl et al. (2021), for teachers it is supportive environments consisting of soft and hard factors that can facilitate the integration of technologies and thus increase the use of technologies. Our study showed that it is often teachers themselves who create these supportive environments. This supportive environment involves both hard and soft factors. 
According to $\mathrm{O}^{\prime} \mathrm{Neal}$ et al. (2017), teachers need more support than is offered now when integrating technologies into teaching and learning. This finding was not confirmed in our study. Teachers in our study indicate that they see themselves as technologically capable enough to integrate technologies into teaching and learning mathematics at the beginning of secondary school. One reason for this positive self-assessment could be that mathematics teachers have been using modern technologies in upper secondary school mathematics for several years. In case problems arise, they are solved through informal networks and support at the school site, based on the feedback in our study. That teachers see themselves as capable to integrate technologies could be related to the fact that using technologies in teaching and learning mathematics in the upper secondary school is standard.

Similar to support for using technologies for teaching and learning mathematics, our study also provides contrasting results regarding teachers' confidence and self-attributed competencies for using technologies. According to the studies of Bingimlas (2009), and Mailizar et al. (2020), mathematics teachers complain about lack of confidence and competencies in using technologies for teaching and learning mathematics. The results of our study indicate that teachers in our study characterise themselves as capable for integrating technologies into teaching and learning mathematics. If teachers describe themselves as capable enough for integrating technologies into teaching and learning, they are likely to have sufficient confidence and selfattributed competencies in using technologies. This sufficient confidence and self-attributed competencies of the mathematics teachers in our study could stem, among other things, from the fact that using technologies in the standardised, national written school-leaving examination has been mandatory for years. This use of technologies in the school-leaving examination has led to the need to integrate technologies into the teaching and learning mathematics in upper secondary schools. Since many upper secondary mathematics teachers also teach lower secondary mathematics in Austria, the experience and confidence of using technologies in upper secondary education may have carried over to lower secondary education.

Regarding the multiple uses of technologies in teaching and learning mathematics (Borba et al., 2016; Drijvers et al., 2010; Lavicza et al., 2015; Trgalová et al., 2018; Yeo, 2020), the results of our study indicate that only a limited number of these possibilities are mentioned by the teachers of our study. High importance and high expectations are given by the teachers in our study to distributing resources, organising and structuring materials, communication between teachers and students, and using technologies to perform calculations. Student-centred approaches such as using technologies to discover mathematical concepts independently or up-to-date technical features such as automatic and adaptive feedback were not mentioned by the teachers of our study.

Regarding the beliefs about teaching and learning mathematics using technologies (Goos et al., 2003), the results of our study indicate that the teachers of our study attribute the roles of servant, partner or combination of servant and partner to technologies. In this context, the classification servant, i.e., using technologies to perform calculations quickly and reliably, was found to have negative connotations by the teachers of our study. This negative connotation of the servant approach comes from the circumstance that teachers in our study fear that replacing mental or penand-paper calculation could lead to students having problems both in building calculation skills and in mathematical thinking. Teachers in our study have high hopes for the partner approach, i.e., the use of technology to facilitate understanding and exploration of different perspectives. In this context, teachers in our study hope that using technologies will facilitate individualising and differentiating teaching and learning mathematics. This facilitation through using technologies should happen, among other things, by offering students additional explanations or tasks, or by making learning processes more independent of time and place.

Our study showed that teachers' anticipated concerns and benefits of integrating technologies into teaching and learning mathematics are balanced. Fears are often associated with traditional or noncontemporary approaches and technologies, such as drill-and-practice approaches or handheld calculators.

In our study, the hopes for teaching and learning mathematics with technologies were mainly associated with contemporary uses of technologies. In this context, teachers hope that learning processes can be individualised, and teaching can be differentiated more easily. Technology-enhanced individualised learning could occur outside the classroom with mobile devices. In addition to greater temporal flexibility, teachers hope that the intensity and scope of learning can also be better adapted to individual needs. This individualised learning also goes hand in hand with differentiated teaching. With differentiated teaching, the teachers hope that different representations of mathematical content or tailored feedback can be more easily integrated into teaching and learning mathematics.

What also emerged in our study is that the most advanced technologies or approaches are not yet associated with school-based learning by teachers themselves. These state-of-the-art technologies or approaches include augmented reality, 3D printing or adaptive learning and learning environments. 


\section{LIMITATIONS}

When investigating teachers' anticipated concerns and benefits of integrating technologies into teaching and learning mathematics, we used case study and grounded theory approaches, and focused our exploratory study on Austria. Since Austria is a very wealthy country, the results of our study should also be interpreted from this point of view. In order to be able to generalise the results of our study more, data from other and especially less wealthy countries would have to be included.

A specific feature of case studies or grounded theory approaches is that a small number of data points (in our case mathematics teachers) are included in the research. This small number of data points allows to obtain indepth information on a yet unknown phenomenon (integrating modern technologies in the first year of secondary education). However, for this information to have a higher degree of generalisability, the next step is to increase the size of the sample.

Although our research focused on integrating technologies into the teaching and learning mathematics in the first year of secondary education in Austria, the results of our study should also be of interest to a wider scientific and practice audience. Teachers' anticipated concerns and benefits are a part of teachers' beliefs and how teacher competencies for integrating technologies into teaching are acquired represent a possible new and additional approach to professional teacher development in the 21st century.

Author contributions: All authors have sufficiently contributed to the study, and agreed with the results and conclusions.

Funding: No funding source is reported for this study.

Declaration of interest: No conflict of interest is declared by authors.

\section{REFERENCES}

Almanthari, A., Maulina, S., \& Bruce, S. (2020). Secondary school mathematics teachers' views on e-learning implementation barriers during the COVID-19 pandemic: The case of Indonesia. Eurasia Journal of Mathematics, Science and Technology Education, 16(7), em1860. https://doi.org/10.29333/ejmste/8240

Attard, C., Calder, N., Holmes, K., Larkin, K., \& Trenholm, S. (2020). Teaching and learning mathematics with digital technologies. In J. Way, C. Attard, J. Anderson, J. Bobis, H. McMaster, \& K. Cartwright (Eds.), Research in mathematics education in Australasia 2016-2019 (pp. 319-347). Springer Singapore. https://doi.org/10.1007/978-981-154269-5_13

Barana, A., Fioravera, M., \& Marchisio, M. (2017). Teacher training: A model for introducing innovative digital methodologies for learning
Mathematics. In Proceedings of the 3rd International Conference on Higher Education Advances (HEAd'17) (pp. 608-616). https://doi.org/10.4995/HEAD17. 2017.5303

Bingimlas, K. A. (2009). Barriers to the successful integration of ICT in teaching and learning environments: A review of the literature. Eurasia Journal of Mathematics, Science and Technology Education, 5(3), 235-245. https:/ / doi.org/10.12973/ ejmste/75275

Borba, M. C., Askar, P., Engelbrecht, J., Gadanidis, G., Llinares, S., \& Aguilar, M. S. (2016). Blended learning, e-learning and mobile learning in mathematics education. ZDM, 48(5), 589-610. https: / / doi.org/10.1007/s11858-016-0798-4

Braun, V., \& Clarke, V. (2006). Using thematic analysis in psychology. Qualitative Research in Psychology, 3(2), 77-101. https://doi.org/10.1191/1478088706 qp063oa

Breit, S., Eder, F., Krainer, K., Schreiner, C., Seel, A., \& Spiel, C. (2019). Nationaler Bildungsbericht Österreich 2018. Band 1 [National Education Report Austria 2018. Volume 1].

Breuer, F., Dieris, B., \& Lettau, A. (2009). Reflexive grounded theory: Eine einführung für die forschungspraxis (2009th ed.). VS Verlag für Sozialwissenschaften.

Bruneforth, M., Lassnigg, L., Vogtenhuber, S., Schreiner, C., \& Breit, S. (2016). Nationaler Bildungsbericht Österreich 2015 [National Education Report Austria 2015]. Leykam.

Charmaz, K. (2002). Qualitative interviewing and grounded theory analysis. In J. F. Gubrium \& J. A. Holstein, Handbook of interview research: Context $\mathcal{E}$ method (pp. 675-694). SAGE Publications, Inc. https:/ / doi.org/10.4135/9781412973588

Charmaz, K. (2006). Constructing grounded theory: A practical guide through qualitative analysis (1 edition). SAGE Publications Ltd.

Cohen, L., Manion, L., \& Morrison, K. (2007). Research methods in education (Sixth ed.). Routledge. https: / / doi.org/10.4324/9780203029053

Donevska-Todorova, A., \& Trgalova, J. (2017). Learning mathematics with technology. A review of recent CERME research.

Drijvers, P., Kieran, C., Mariotti, M.-A., Ainley, J., Andresen, M., Chan, Y. C., Dana-Picard, T., Gueudet, G., Kidron, I., Leung, A., \& Meagher, M. (2010). Integrating technology into mathematics education: Theoretical perspectives. In C. Hoyles \& J.-B. Lagrange (Eds.), Mathematics education and technology-rethinking the terrain: The 17th ICMI Study (pp. 89-132). Springer US. https://doi.org/10.1007 /978-1-4419-0146-0_7 
Dwyer, D. C. (1990). The evolution of teachers' instructional beliefs and practices in high-access-to-technology classrooms [Paper presentation]. Annual meeting of the educational research association. https: / / files.eric.ed.gov/fulltext/ED325074.pdf

Eisenhardt, K. M. (1989). Building theories from case study research. Academy of Management Review, 14(4), 532-550. https://doi.org/10.5465/amr.1989. 4308385

Ezzy, D. (2002). Qualitative analysis: Practice and innovation. Allen \& Unwin.

Ferchhoff, W. (2007). Jugend und jugendkulturen im 21. Jahrhundert-Lebensformen und lebensstile [Youth and Youth Cultures in the 21st Century Lifestyles and Lifestyles].

Flood, V. J., Shvarts, A., \& Abrahamson, D. (2020). Teaching with embodied learning technologies for mathematics: Responsive teaching for embodied learning. ZDM, 52(7), 1307-1331. https:/ / doi.org/10.1007/s11858-020-01165-7

Glaser, B. G., \& Strauss, A. L. (1999). Discovery of grounded theory: Strategies for qualitative research. AldineTransaction.

Gläser, J., \& Laudel, G. (2010). Experteninterviews und qualitative Inhaltsanalyse [Expert interviews and qualitative content analysis]. Springer-Verlag. https:/ / doi.org/10.1007/978-3-531-91538-8

Goos, M., Galbraith, P., Renshaw, P., \& Geiger, V. (2003). Perspectives on technology mediated learning in secondary school mathematics classrooms. The Journal of Mathematical Behavior, 22(1), 73-89. https: / / doi.org/10.1016/S0732-3123(03)00005-1

Hoyles, C., Noss, R., Kent, P., \& Bakker, A. (2010). Improving mathematics at work: The need for technomathematical literacies. Routledge. https://doi.org/ 10.4324/9780203854655

Inayat, M. F., \& Hamid, S. N. (2016). Integrating new technologies and tools in teaching and learning of mathematics: An overview. Journal of Computer and Mathematical Sciences, 7(3), 122-129.

Jacinto, H., \& Carreira, S. (2017). Mathematical problem solving with technology: The techno-mathematical fluency of a student-with-GeoGebra. International Journal of Science and Mathematics Education, 15(6), 1115-1136. https://doi.org/10.1007/s10763-0169728-8

Kent, P., Bakker, A., Hoyles, C., \& Noss, R. (2005). Techno-mathematical Literacies in the Workplace. Mathematics Statistics and Operational Research, 5(1), 5-9. https:/ / doi.org/10.11120/msor.2005.05010016

Larkin, K., \& Calder, N. (2016). Mathematics education and mobile technologies. Mathematics Education Research Journal, 28(1), 1-7. https:/ / doi.org/10.1007 / s13394-015-0167-6
Larkin, K., \& Milford, T. (2018). Mathematics apps Stormy with the weather clearing: Using cluster analysis to enhance app use in mathematics classrooms. In Using mobile technologies in the teaching and learning of mathematics (pp. 11-30). Springer. https://doi.org/10.1007/978-3-31990179-4_2

Lavicza, Z., Juhos, I., Koren, B., Fenyvesi, K., Csapodi, C., Kis, M., \& Mantecón, J.-D. (2015). Integrating technology into primary and secondary school teaching to enhance mathematics education in Hungary. In CERME 9-Ninth Congress of the European Society for Research in Mathematics Education (pp. 2430-2431). https://doi.org/10.3390 /isis-summit-vienna-2015-T1.1007

Lemmer, C. A. (2013). A view from the flip side: Using the inverted classroom to enhance the legal information literacy of the international LL. M. student. Law Library Journal, 105(4), 461-491.

Mailizar, A., Abdulsalam, M., \& Suci, B. (2020). Secondary school mathematics teachers' views on e-learning implementation barriers during the COVID-19 pandemic: The case of Indonesia. Eurasia Journal of Mathematics, Science \& Technology Education, 16(7), em1860. https://doi.org/10.29333 / ejmste/ 8240

Mey, G., \& Mruck, K. (2011). Grounded theory reader (2nd ed.). VS Verlag für Sozialwissenschaften. https: / / doi.org/10.1007/978-3-531-93318-4

Mishra, P. (2019). Considering contextual knowledge: The TPACK diagram gets an upgrade. Journal of Digital Learning in Teacher Education, 35(2), 76-78. https:/ / doi.org/10.1080/21532974.2019.1588611

Mishra, P., \& Koehler, M. J. (2006). Technological pedagogical content knowledge: A framework for teacher knowledge. Teachers College Record, 108(6), 1017. https://doi.org/10.1111/j.1467-9620.2006. 00684.x

O’Neal, L. J., Gibson, P., \& Cotten, S. R. (2017). Elementary school teachers' beliefs about the role of technology in 21st-century teaching and learning. Computers in the Schools, 34(3), 192-206. https:// doi.org/10.1080/07380569.2017.1347443

Ottenbreit-Leftwich, A. T., Glazewski, K. D., Newby, T. J., \& Ertmer, P. A. (2010). Teacher value beliefs associated with using technology: Addressing professional and student needs. Computers $\mathcal{E}$ Education, 55(3), 1321-1335. https://doi.org/ 10.1016/j.compedu.2010.06.002

Philipp, R. A. (2007). Mathematics teachers' beliefs and affect. Second Handbook of Research on Mathematics Teaching and Learning, 1, 257-315.

Ridder, H. (2016). Case study research: Approaches. In W. Matiaske, M. Spieß, et al. (Eds.), 
Sozialwissenschaftliche Forschungsmethoden (Vol. 12). Rainer Hampp Verlag.

Rosenkranz, L. (2017). Qualitative forschungsprinzipien der grounded theory. In L. Rosenkranz (Ed.), Exzessive nutzung von onlinespielen im jugendalter (pp. 83-94). Springer Fachmedien Wiesbaden. https:/ / doi.org/10.1007/978-3-658-15360-1_5

Selter, C., Gräsel, C., Reinold, M., \& Trempler, K. (2015). Variations of in-service training for primary mathematics teachers: An empirical study. ZDM, 47(1), 65-77. https://doi.org/10.1007/s11858-0140639-2

Shulman, L. S. (1986). Those who understand: Knowledge growth in teaching. Educational Researcher, 15(2), 4-14. https://doi.org/10.3102/ 0013189X015002004

Sinclair, N. (2020). On teaching and learning mathematics-technologies. In STEM teachers and teaching in the digital era (pp. 91-107). Springer. https: / / doi.org/10.1007/978-3-030-29396-3_6

Sipilä, K. (2014). Educational use of information and communications technology: Teachers' perspective. Technology, Pedagogy and Education, 23(2), 225-241. https:/ / doi.org/10.1080/1475939X. 2013.813407

Smith, R. C., Kim, S., \& McIntyre, L. (2016). Relationships between prospective middle grades mathematics teachers' beliefs and TPACK. Canadian Journal of Science, Mathematics and Technology Education, 16(4), 359-373.

https:/ / doi.org/10.1080/14926156.2016.1189624

Strauss, A., \& Corbin, J. M. (1990). Basics of qualitative research: Grounded theory procedures and techniques. Sage Publications, Inc.
Strauss, A., \& Corbin, J. M. (1997). Grounded theory in practice. Sage.

Thurm, D., \& Barzel, B. (2020). Effects of a professional development program for teaching mathematics with technology on teachers' beliefs, self-efficacy and practices. ZDM, 52(7), 1411-1422. https://doi.org/10.1007/s11858-020-01158-6

Trgalová, J., Clark-Wilson, A., \& Weigand, H. (2018). Technology and resources in mathematics education. Routledge. https:/ / doi.org/10.4324/9781315113562-12

Vitabar, F., Lavicza, Z., \& Hohenwarter, M. (2019). Developing professional development programmes with gamification for mathematics teachers in Uruguay. Eleventh Congress of the European Society for Research in Mathematics Education, Utrecht University, Feb 2019, Utrecht, Netherlands.

Weinhandl, R., Lavicza, Z., Houghton, T., \& Hohenwarter, M. (2021). A look over students' shoulders when learning mathematics in homeschooling. International Journal of Mathematical Education in Science and Technology, 1-21. https://doi.org/10.1080/0020739X.2021.1912423

Wrona, T. (2005). Die Fallstudienanalyse als wissenschaftliche Forschungsmethode [The case study analysis as a scientific research method]. ESCPEAP, Europ. Wirtschaftshochsch.

Yeo, S. (2020). Integrating digital technology into elementary mathematics: Three theoretical perspectives. Research in Mathematical Education, 23(3), 165-179.

\section{http://www.ejmste.com}

